\title{
Research Paper \\ The Effect of Cardiac Rehabilitation on Endostatin Levels in Patients With Ath- erosclerosis After Coronary Artery Bypass Grafting
}

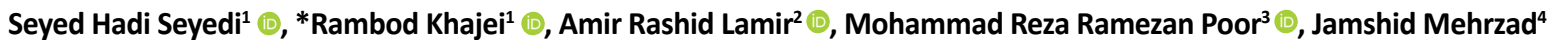

1.Department of Physical Education \& Sport Sciences, Neyshabour Branch, Islamic Azad University, Neyshabour, Iran.

2. Department of Physical Education \& Sport Sciences, Ferdowsi University, Mashhad, Iran.

3. Department of Physical Education \& Sport Sciences, Mashhad Branch, Islamic Azad University, Mashhad, Iran.

4. Department of Biochemistry Sciences, Neyshabour Branch, Islamic Azad University, Neyshabour, Iran.

\begin{tabular}{|c|c|}
\hline \multirow{3}{*}{$\begin{array}{l}\text { Use vour device to scan } \\
\text { and read the article online } \\
\text { and }\end{array}$} & \\
\hline & $\begin{array}{l}\text { Citation: Seyedi SH, Khajei R, Rashid Lamir A, Ramezan Poor MR, Mehrzad J. [The Effect of Cardiac Rehabilitation on } \\
\text { Endostatin Levels in Patients With Atherosclerosis After Coronary Artery Bypass Grafting (Persian)]. Journal of Arak University } \\
\text { of Medical Sciences (JAMS). 2020; 23(4):498-511. https://doi.org/10.32598/JAMS.23.4.6101.1 }\end{array}$ \\
\hline & doi)https://doi.org/10.32598/JAMS.23.4.6101.1 \\
\hline
\end{tabular}

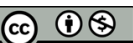

Article Info:

Received: 29 Jan 2020

Accepted: 09 Jun 2020

Available Online: 01 Oct 2020

Keywords:

Endostatin, Aerobic resistance training, CABG patients

\section{ABSTRACT}

Background and Aim Coronary Artery Disease (CAD) is one of the leading causes of death and mortality in today's societies. Physical activity increases some of the influential factors for this disease. The purpose of this study was to investigate the effect of 8 weeks of aerobic and resistance training on endostatin in patients with Coronary Artery Bypass Graft (CABG).

Methods \& Materials The study participants were 24 male patients who were randomly divided into the experimental $(n=12)$ and control $(n=12)$ groups with Mean $\pm S D$ age of $55.37 \pm 6.90$ years, weight $75.45 \pm 5.87 \mathrm{~kg}$, height $173.27 \pm 3.36 \mathrm{~cm}$ and body mass index of $25.11 \pm 1.55 \mathrm{~kg} / \mathrm{m}^{2}$. The experimental group performed 8 weeks of aerobic and resistance training ( 3 sessions per week and 1.5 hours per session) based on the measurements, while the control group did not exercise during this period. To measure endostatin concentrations, blood samples were taken 48 hours before and 48 hours after the last training session while all subjects were fasting. Data were analyzed using the Shapiro-Wilk test to normalize the data and Student t-test in independent and correlated groups at the significant level of 0.05 . Ethical Considerations This article was ethically approved by Azad University of Neyshabur (Ethics Code IR.IAU.NEYSHABUR.REC.1398.018) and with the Clinical Trial Code IRCT20191228045916N1 in the Iranian Registry of Clinical Trials.

Results The present study showed that the aerobic and resistance training group significantly decreased endostatin concentrations $(\mathrm{P}=0.001)(\mathrm{t}=1.672)$ compared with the control group.

Conclusion Based on the findings, aerobic and resistance training decreases endostatin concentrations, known as an anti-angiogenic factor.

\section{Extended Abstract}

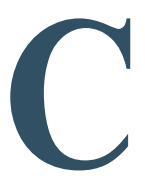

\section{Introduction}

oronary heart disease is one of the leading causes of death in today's society [1]. Patients with myocardial infarction and those who have undergone surgery, despite the improvement of the symptoms of the disease and the relative increase in life expectancy, suffer from problems such as insufficient useful life, multiple hospitalizations, and psychological and social problems. Accordingly, some researchers suggest dif-

\section{* Corresponding Author:}

Rambod Khajei, PhD.

Address: Department of Physical Education \& Sport Sciences, Neyshabour Branch, Islamic Azad University, Neyshabour , Iran

Tel: +98 (915) 1141409

E-mail: r.khajeie@gmail.com 
ferent exercises to improve the quality of life and increase the functional capacity of these patients [2].

In the study of Banerjee et al. it was reported that exercise capacity is the strongest predictor of deaths caused by cardiovascular events [3, 4]. This study has also shown that muscle strength and functional capacity are reduced in heart patients. Due to its attractiveness and low cost, exercise can be an incentive for patients to participate in (cardiac) rehabilitation programs and can be used in the form of multidisciplinary programs to increase mental health, functional capacity and quality of life of cardiovascular patients [5]. The aim of this study was to evaluate the effect of eight weeks of resistance-aerobic training on endostatin levels in patients with Coronary Artery Bypass Grafting (CABG).

\section{Materials and Methods}

The participants of this study consisted of 24 male patients with a mean age of $55.37 \pm 6.90$ years, weight $75.45 \pm 5.87 \mathrm{~kg}$, height $173.27 \pm 3.36 \mathrm{~cm}$, and body mass index $1.55 \pm 25.11 \mathrm{~kg} / \mathrm{sq}$ (Table 1), who were randomly divided into experimental $(n=12)$ and control $(n=12)$ groups. According to the assessments (cardiopulmonary status and exercise tolerance test), the experimental group performed eight weeks of resistance-aerobic exercise for one to one and a half hours ( 3 sessions per week) and the control group was without exercise during this period. To measure endostatin levels, blood samples were taken 48 hours before the start of the protocol and also 48 hours after the last session of the protocol while all subjects were fasting (Table 2). For data analysis, Shapiro-Wilk test was used to normalize the data and Student's t-test was used in independent and correlated groups at a significance level of 0.05 .

\section{Results}

The normality of the data was evaluated using ShapiroWilk test. Data analysis in correlated and dependent groups was performed by paired-sample t-tests using SPSS V. 21 at a significant level of $\mathrm{P} \leq 0.05$.

The results showed that in the aerobic-resistance exercise group, a significant decrease was observed in endostatin levels ( $\mathrm{P}=0.001)(\mathrm{T}=1.672)$ compared to the control group (Table 3). Also, paired-sample t-test data based on the pre-test and post-test measurements in the experimental group showed a significant decrease in endostatin levels $(\mathrm{P}=0.001)(\mathrm{T}=7.883)$ (Figure 1).

\section{Discussion and Conclusion}

One of the most important anti-angiogenic factors of endostatin is that according to the results of many studies, this variable is affected by sports activities [31-37]. Studies show that endurance exercise increases the shear stress of bloodstream, increases the activity of endothelial nitric oxide synthetase and increases the antioxidant capacity, which has positive effects on endothelial function, especially in cardiovascular patients [32-34]. Brixius et al. (2008) reported that endostatin levels decreased in response to prolonged aerobic activity in obese men [45].

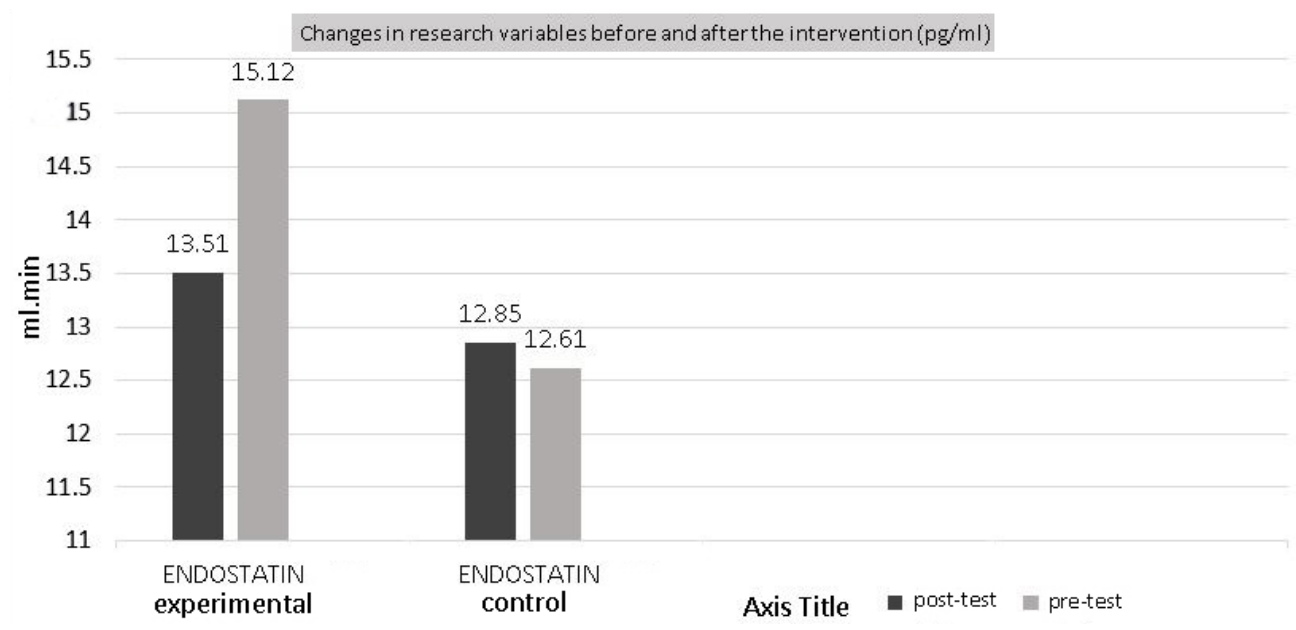

Figure 1. Mean of variables between the two groups before and after the training period $(\mathrm{pg} / \mathrm{ml})$

This figure shows the changes in research variables in the aerobic-resistance training group compared to the control group. 
Table 1. Specifications of the participants

\begin{tabular}{ccccc}
\hline \multirow{2}{*}{ Groups } & \multicolumn{4}{c}{ Mean \pm SD } \\
\cline { 2 - 5 } & Age $(\mathbf{Y})$ & Height $(\mathbf{c m})$ & Weight $(\mathbf{k g})$ & BMI \\
\hline Control & $56.16 \pm 7.50$ & $173.50 \pm 3.69$ & $76.16 \pm 5.23$ & $25.28 \pm 1.34$ \\
Experimental & $54.58 \pm 6.47$ & $173.04 \pm 3.15$ & $74.75 \pm 6.60$ & $24.94 \pm 1.80$ \\
\hline
\end{tabular}

Table 2. Combined rehabilitation program

\begin{tabular}{|c|c|c|c|c|c|c|c|c|c|c|c|}
\hline \multicolumn{3}{|c|}{ Exercise } & $\begin{array}{c}\text { Week } \\
\text { Intensity }\end{array}$ & First & Second & Third & Fourth & Fifth & Sixth & Seventh & Eighth \\
\hline \multirow{7}{*}{ 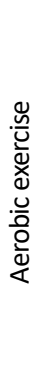 } & \multirow{2}{*}{ Treadmill } & Intensity (percentage) & $60-80$ & 60 & 60 & 65 & 65 & 70 & 75 & 75 & 80 \\
\hline & & Duration (minutes) & $20-30$ & 20 & 20 & 33 & 24 & 26 & 28 & 30 & 30 \\
\hline & \multirow{3}{*}{ Arm ergometer } & Intensity (percentage) & $30-50$ & 30 & 30 & 35 & 35 & 40 & 45 & 45 & 50 \\
\hline & & & & & & & & & & & \\
\hline & & Duration (minutes) & $8-10$ & 8 & 8 & 9 & 9 & 9 & 10 & 10 & 10 \\
\hline & \multirow{2}{*}{ Ergometer bike } & Intensity (percentage) & $30-50$ & 30 & 30 & 35 & 35 & 40 & 45 & 45 & 50 \\
\hline & & Duration (minutes) & $10-12$ & 10 & 10 & 10 & 11 & 11 & 11 & 12 & 12 \\
\hline \multirow{3}{*}{ 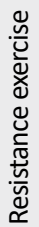 } & The patient's body parts & & $7-15$ & $7-10$ & $10-15$ & & & & & & \\
\hline & $\begin{array}{l}\text { Yellow } \\
\text { Thera-Band }\end{array}$ & $\begin{array}{c}\text { Intensity } \\
\text { (number of repetitions) }\end{array}$ & $7-15$ & & & $7-10$ & $10-13$ & $13-15$ & & & \\
\hline & $\begin{array}{c}\text { Pink } \\
\text { Thera-Band }\end{array}$ & & $7-15$ & & & & & & $7-10$ & $10-13$ & $13-15$ \\
\hline
\end{tabular}

Table 3. Intragroup and intergroup changes of research variables $(\mathrm{P} \leq 0.005)$

\begin{tabular}{ccccccc}
\hline Variables & \multicolumn{2}{c}{ Intergroup Changes } & \multicolumn{2}{c}{ Intragroup Changes (Control) } & \multicolumn{2}{c}{ Intragroup Changes (Experimental) } \\
\hline Test & $\mathrm{F}$ & $\mathrm{P}$ & $\mathrm{T}$ & $\mathrm{P}$ & $\mathrm{T}$ & $\mathrm{P}$ \\
endostatin & 1.672 & 0.001 & 0.826 & 0.426 & 8.205 & 0.001 \\
\hline
\end{tabular}

Suhr et al. (2010) showed that six months of endurance activity significantly reduced endostatin levels in male runners [46]. Rullman et al. (2007) showed that one session of resistance exercise had no effect on reducing endostatin [48]. The lack of discrepancy between their results and the results of the present study may be due to the dissimilarity of the subjects, exercises and duration of the research. The mechanism of endostatin reduction in response to exercise is not yet known, but it is possible that exercise reduces the rate of metamorphosis in the extracellular matrix, which may prevent endostatin from dissociating from collagen [49].
According to the results of this study, which examined the effect of eight weeks of resistance-aerobic exercise on anti-angiogenic factors, it was found that these exercises increased blood supply to the myositis due to increased angiogenic factors and also by reducing anti-angiogenic agents in the bloodstream had a significant effect on reducing the complications of cardiovascular disease. Also, according to the results of the research consistent with the present study, it is suggested that in patients with cardiovascular disease and $\mathrm{CABG}$ patients, exercise along with other clinical 
therapies - as a non-pharmacological method and efficient prevention - should be considered.

\section{Ethical Considerations}

\section{Compliance with ethical guidelines}

This article was ethically approved by Azad University of Neyshabur (Ethics Code IR.IAU.NEYSHABUR.REC.1398.018) and with the Clinical Trial Code IRCT20191228045916N1 in the Iranian Registry of Clinical Trials.

Funding

The paper was extracted from the $\mathrm{PhD}$. dissertation of the first author, Department of Physical Education \& Sport Sciences, Neyshabour Branch, Islamic Azad University, Neyshabour.

\section{Authors' contributions}

Conceptualization, research method, sampling and drafting: Seyed Hadi Seyedi; Data analysis: Rambod Khajei, Amir Rashid Lamir; Editing and finalization: All authors.

\section{Conflicts of interest}

The authors declared no conflicts of interest.

\section{Acknowledgements}

The authors of this article would like to thank the participants and those who helped in this research, as well as the cardiac rehabilitation department of Javad Al-Aeme Hospital in Mashhad City. 
This Page Intentionally Left Blank 


\title{
تأثير بازتوانى قلبى بر سطوح اندوستاتين در بيمار ان مبتلا به آترواسكلروز يس از باىيس عروق كرونر
}

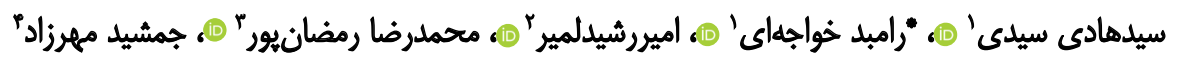

ا. ا.كروه تربيتبدنى و علوم ورزشى، واحد نيشابور، دانشكاه آزاد اسلامى، نيشابور، ايران.

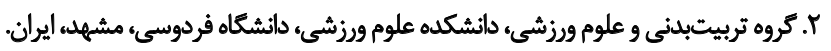

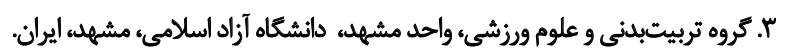

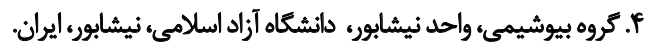

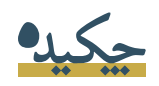

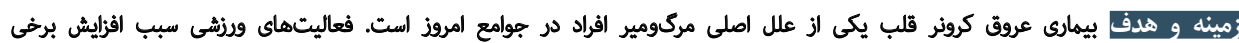

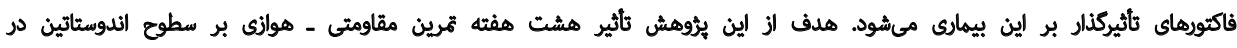

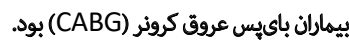

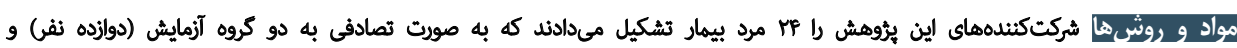

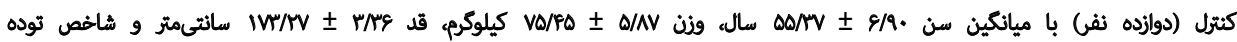

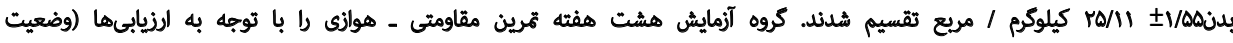

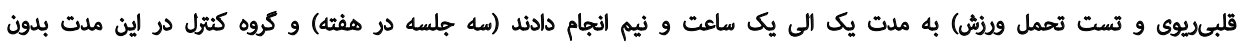

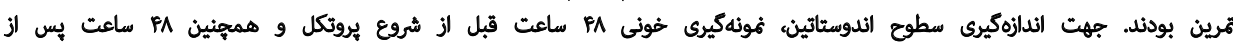

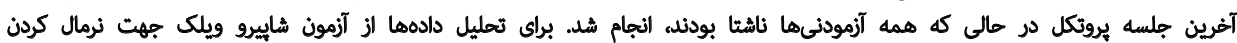

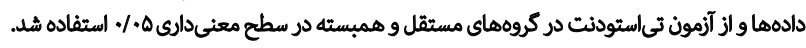

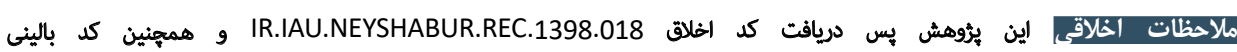
IRCT20191228045916N1

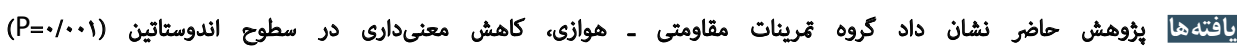
(T=1/FVT)

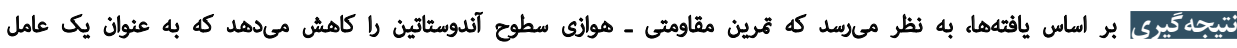

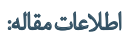

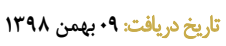

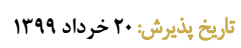

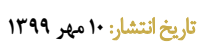

كليدوازٌهها:

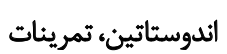

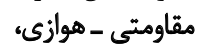
بيماران آترواسكلروز

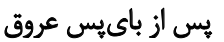
كرونر ازئري
\end{abstract}

خونرسانى به ميوكارد ايجاد مىشود. شايعترين علت ايسكمى ئرئ

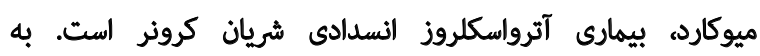

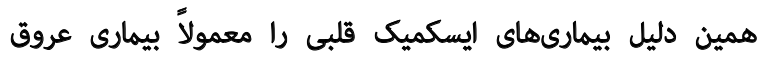

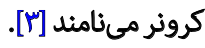

آترواسكلروز به عنوان شايعترين علت ايسكمى ميوكارد،

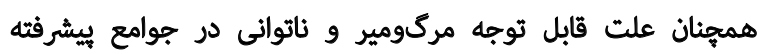

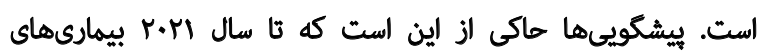

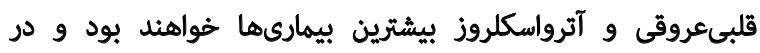

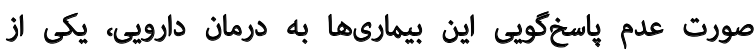

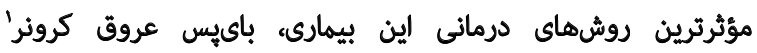

1. Coronary Artery Bypass Graf (CABG)

datên

انفاركتوس ميوكارد يكى از دلايل اصلى مركومير در سرتاسر

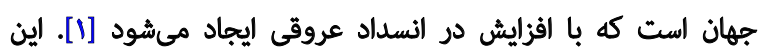

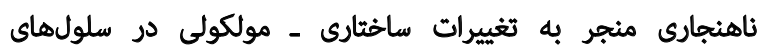

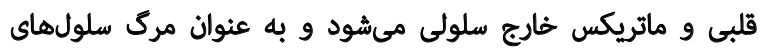

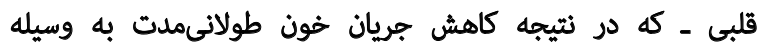

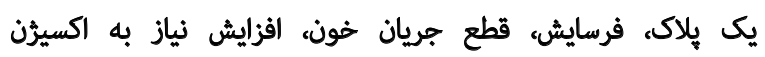

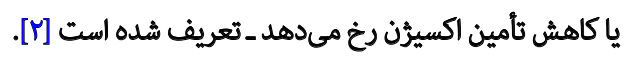

بيمارىهاى ايسكميك قلبى كروهى از سندرمهاى مرتبط باهم هستند كه به دليل محروميت از اكسيرن، ناشى از كاهش

$$
1 .
$$

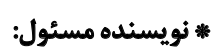

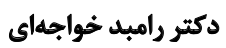

نشانى: نيشابور، دانشكاه آزاد اسلامى، واحد نيشابور، كروه تربيتبدنى و علوم ورزشى.

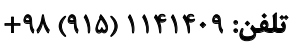
r.khajeie@gmail.com بست الكترونيكى 


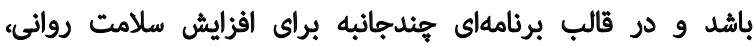

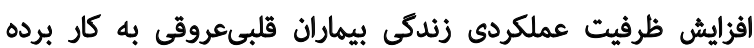

شود [19].

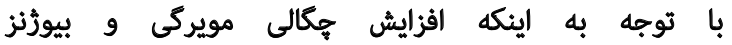

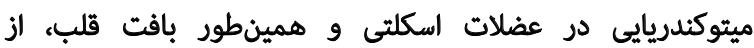

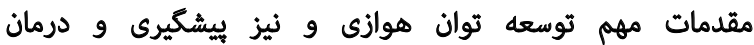

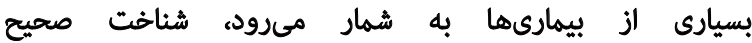

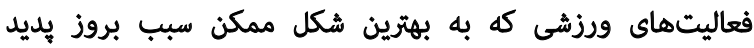

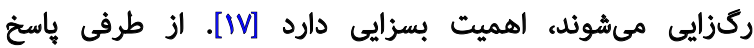

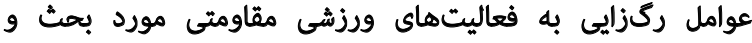

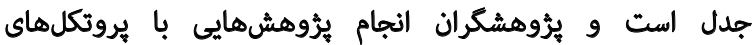

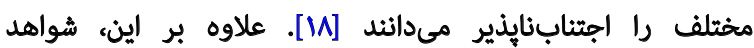

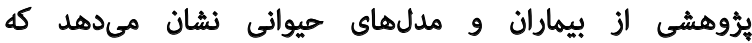

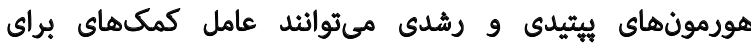

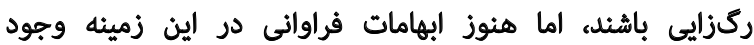

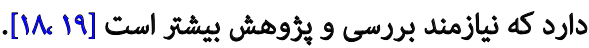

يُروهشها نشان مىدهند هر دو برنامه تمرينى تركيبى و هوازى وني

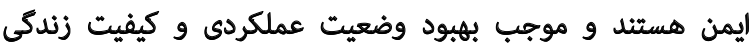

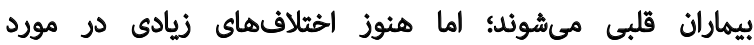

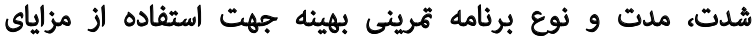

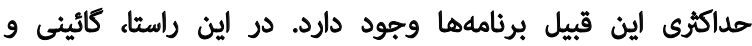

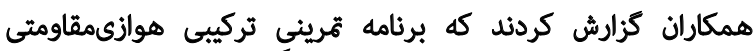

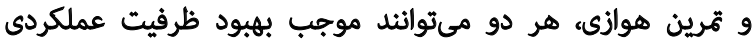

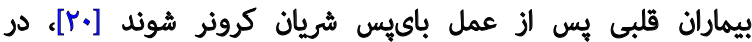

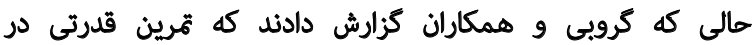

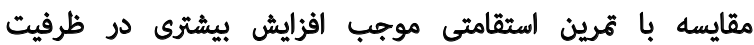

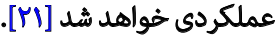

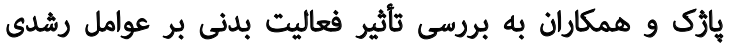

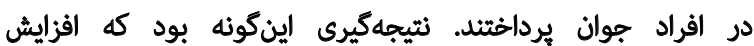

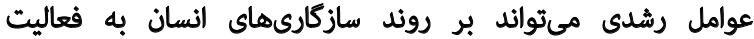

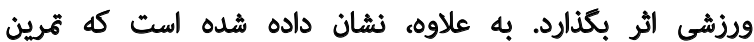

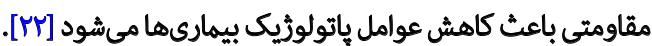

با توجه به اليكه الكثر مطالعات بيشين روى نمونهاى

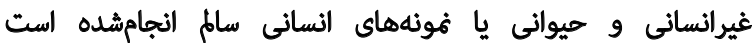

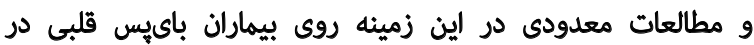

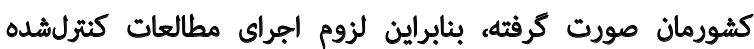

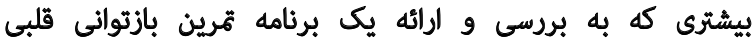

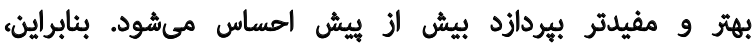

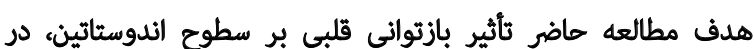

بيهاران مبتلا به آترواسكلروز يس از بائيس عروق كرونئ است.
است [F]. برنامههاى توانبخشى به منظور محدود كردن اثرات

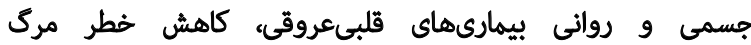

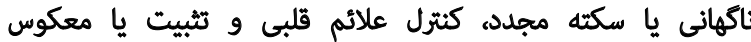

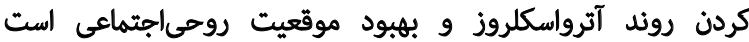

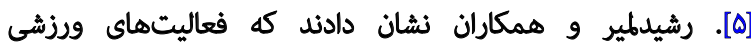
سبب بهبود وضعيت قلب و عروق و و كاهش ريسكانفاكثورهاى آنها مىشود [9]. علوىزاده و همكاران كزارش كردند كه انجام

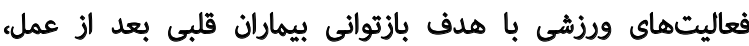

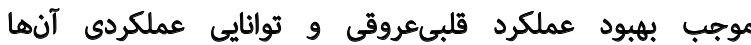

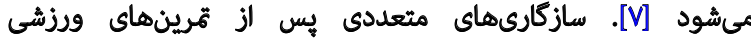

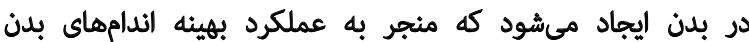

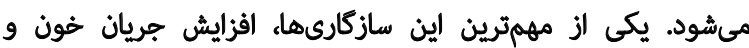

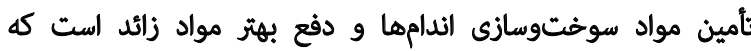

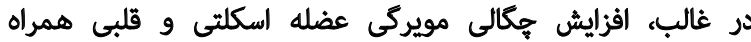

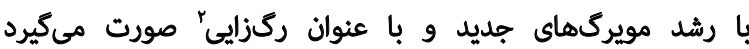

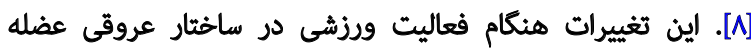
اسكلتى براى رفع شرايط استرسى رخ مى هدهد [q].

هركوئه كاهش در سطوح اكسيرن، مجموعهاى از باسخهاى

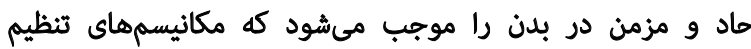

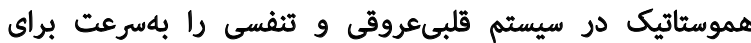

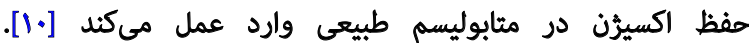

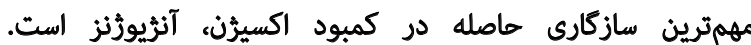

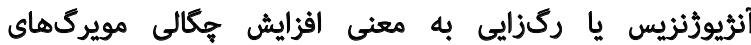

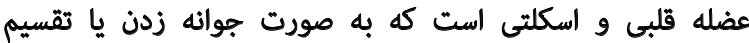
طولى از رك قبلى به وجود مئى آيد و در باسخ به به محركهايى

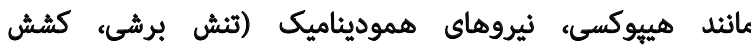

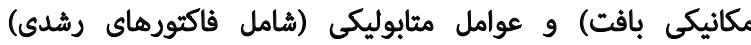

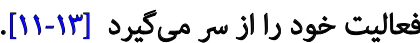

اندوستاتين يكى از مهمترين فاكتورهاى انثيواستاثيكى است

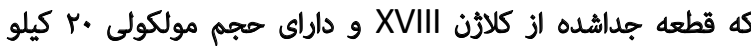

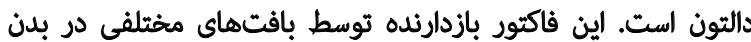

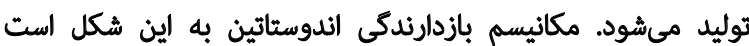

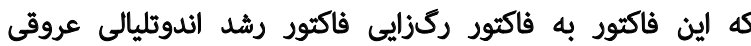

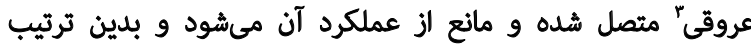

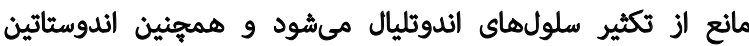

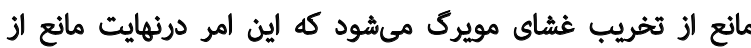

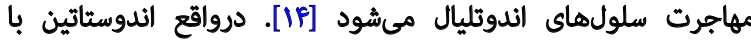

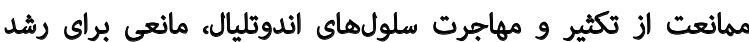

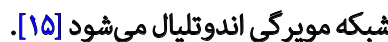

ثرينات ورزشى به سبب كمهزيثه و جذاب بودن مى بوانثن مشوقى براى شركت بيماران در برنامههاى بازتوانى و نوتوانى قلبى بردئ

2. Angiogenesis.

3. Vascular Endothelial Growth Factor (VEGF) 
را طى هر جلسه درمانى انجام دادند. در هر جلسه درمان درمانى، از

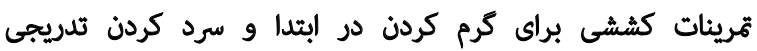

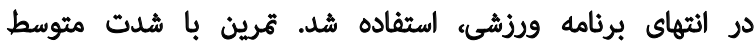

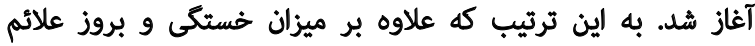

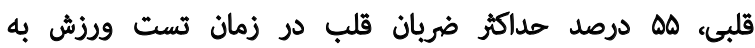

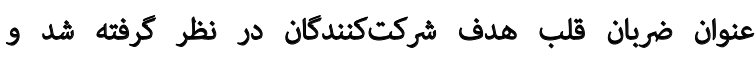

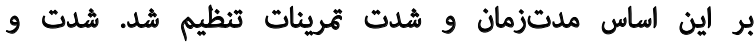

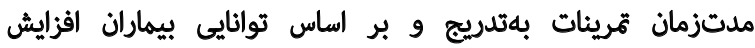

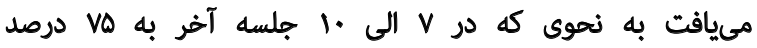

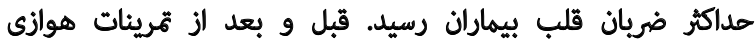

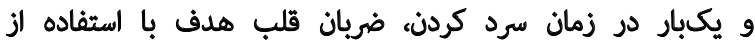

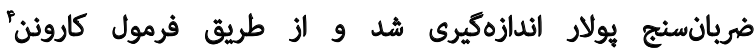
(فرمول شماره ا) محاسبه شد.

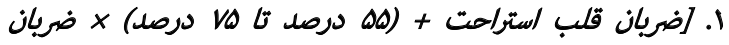

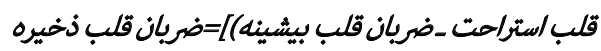

ميزان اضافهبار تمرين: هر هفته با افزايش شدت ثمرين، تقريباً به ميزان ه درصد به ضريان قلب هدف افزوده شد.

تمرين مقاومتى: شركت كنثهها حركات شترينى مشخصشده

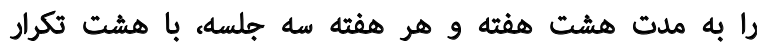

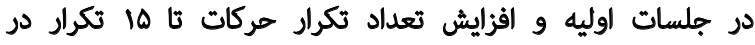

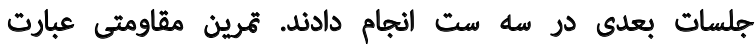

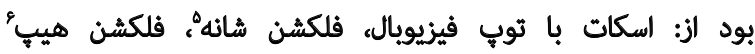

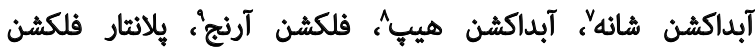

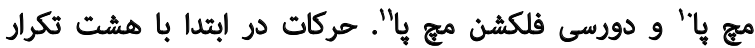

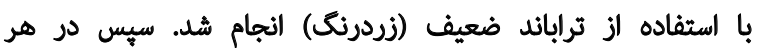

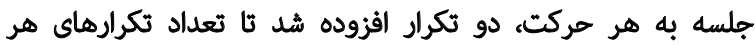

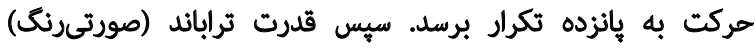

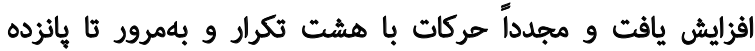

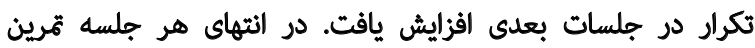

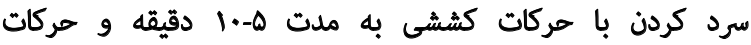

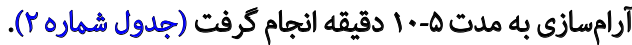

نوسانات ضريان قلب بيهار در ثمام مراحل تمرين توسط سيستم

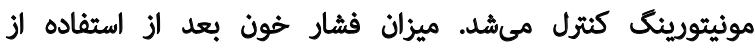

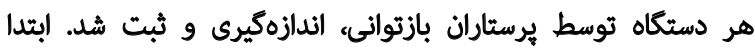

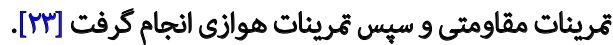

4. Karunen

5. Shoulder flection

6. Hp Flection

7. Shoulder abduction

8. Hip Abduction

9. Elbow Flection

10. Ankle Plantar

11. Ankle Dorsi flection

\section{مواد و روشها}

باين بزوهش الز نوع نيمهتجربى است كه با طرح ييش و يسآزمون

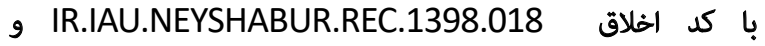

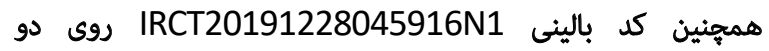

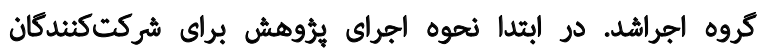

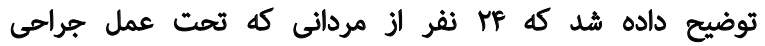

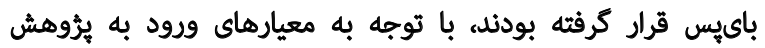

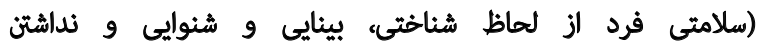

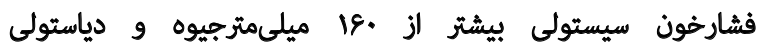

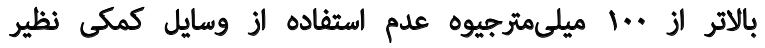

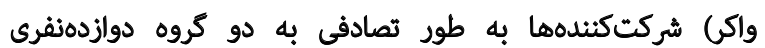

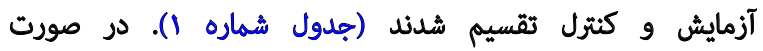

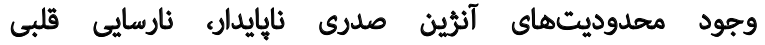

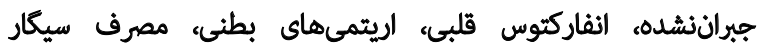

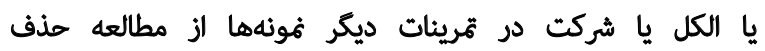

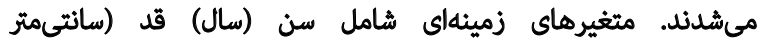

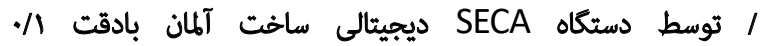

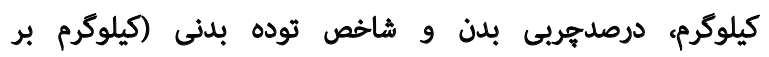

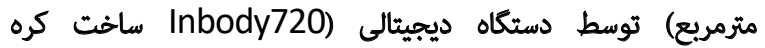
جنوبى)، ضريان قلب (ضريان در دقيقه) توسط دستكاه ضريان سنج يولارمدل F1tm ساخت كشور فنلاند، فشار خون استراحتى توني

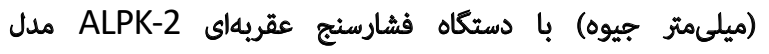

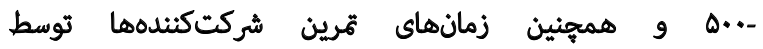

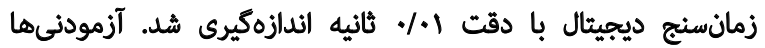

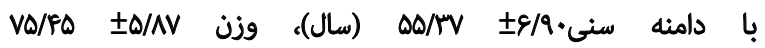

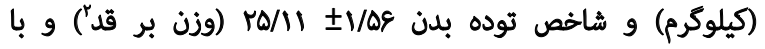

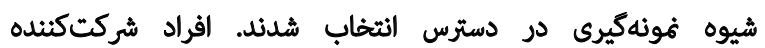

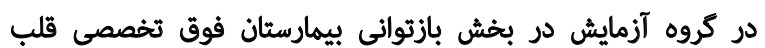

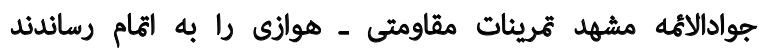

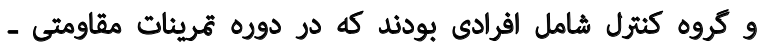

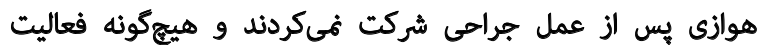

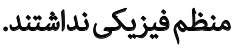

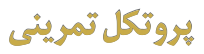

در اين يُؤش برنامه هشتهفتهاي تمرين مقاومتى - هوازى به طور همزمان توسط بيماران انجام شد.

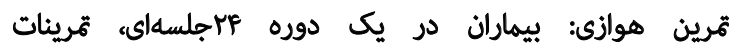

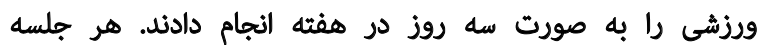

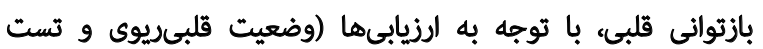

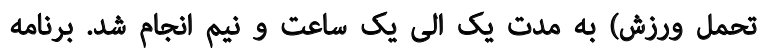

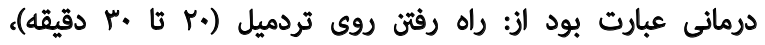

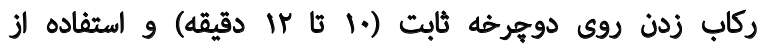

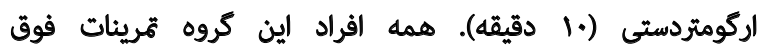


يافتهها

نرمال بودن دادهها با استفاده از آزمون شاييرو ويلك بررسى دادي شد. براى تحليل دادهها در كروههاى همبسته و وابسته، الز آزمون

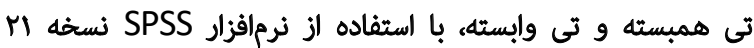

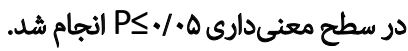

نثايج نشان داد در مقايسه بين كروه ثمرين مقاومثى - هوازى

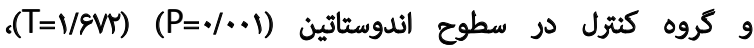

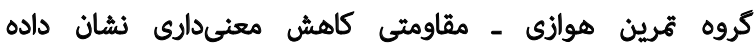

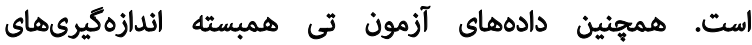

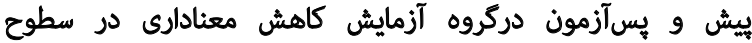

روشهاي آزمايشكاهى و هونهكيرى خون: از تمامى آزمودنىها

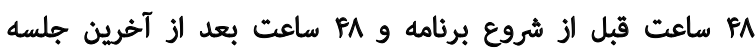

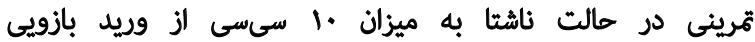

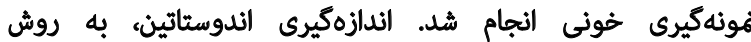
Roche با دستكاه از Calorimetry ساخت كشور آلمان انجام شد. الندازهيرى سطوح الندوستاتين

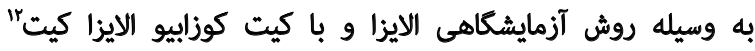

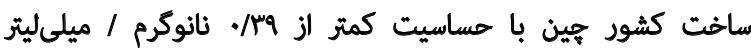

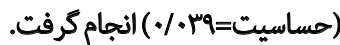

12. Cusabio ELISA kits (china)

جدول ا. مشخصات آزمودنى هاى شركت كننده

\begin{tabular}{|c|c|c|c|c|}
\hline \multicolumn{4}{|c|}{ مياتئين土|نحرافمعيار } & \multirow{2}{*}{ 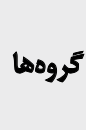 } \\
\hline شاخص توده بلن & وزن (كيلوكرم) & قد (سانتىمتر) & سن (سال) & \\
\hline$r \Delta / / \Lambda \pm 1 / M F$ & $V E / \backslash \notin \pm \Delta / M$ & $\mid V / / \Delta \cdot \pm r / \varepsilon q$ & $\Delta F / / E \pm V / \Delta+$ & كنترل \\
\hline$r f / q \Psi \pm 1 / \lambda$. & $v \in / N \Delta \pm \varepsilon / \varepsilon$. & $|K / \cdot f \pm r /| \Delta$ & $\Delta F / \Delta \Lambda \pm E / F Y$ & أزمايش \\
\hline
\end{tabular}

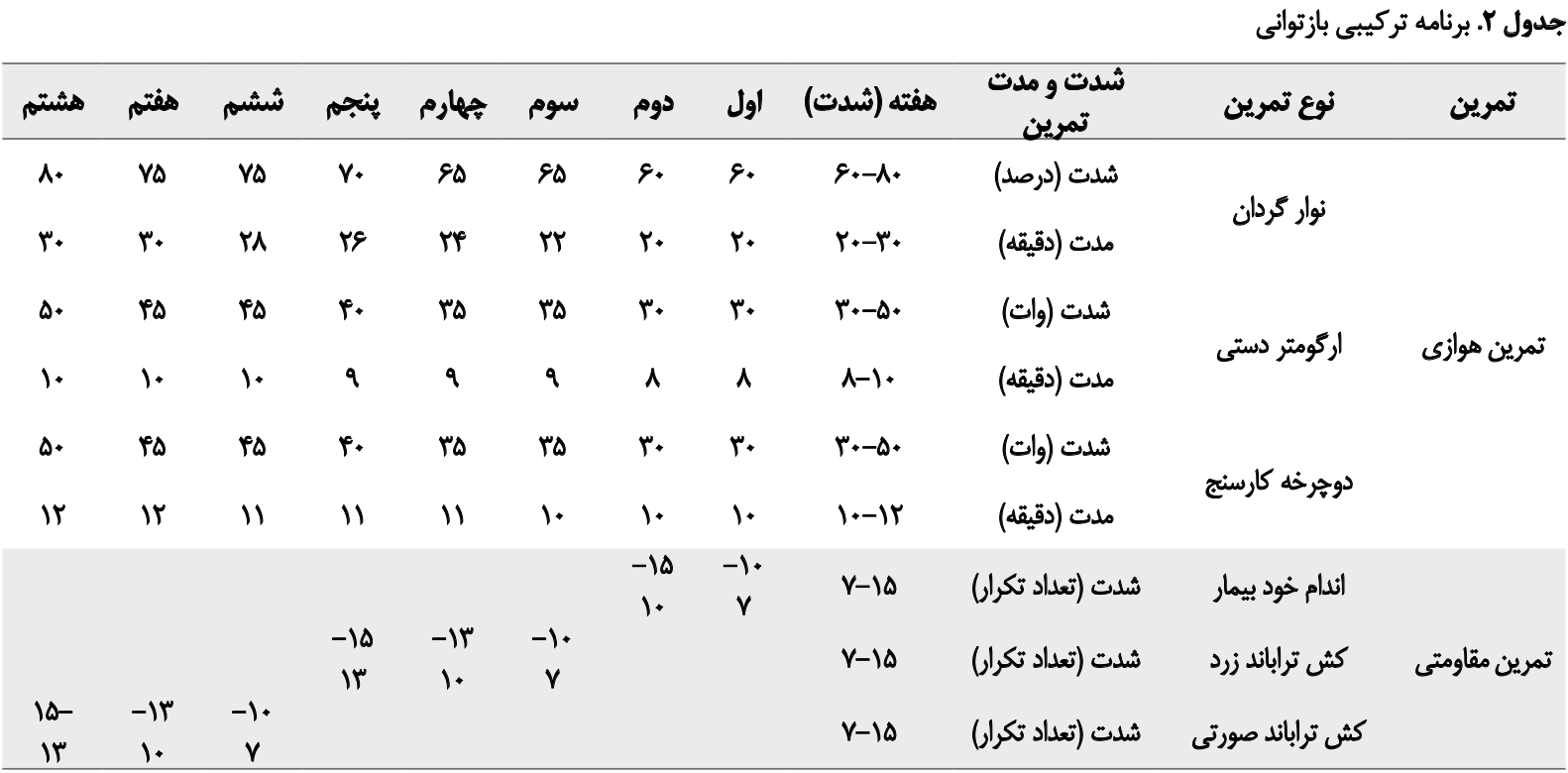

جدول ب. تغييرات درون كروهى و بين كروهى متغيرهاى بثروهش

\begin{tabular}{|c|c|c|c|c|c|c|}
\hline \multicolumn{2}{|c|}{ تغييرات درون كروهي } & \multicolumn{2}{|c|}{ تغيبرات درون كَروهي كيترل } & \multicolumn{2}{|c|}{ تغييرات بين كروهى } & \multirow{2}{*}{ متغيرها } \\
\hline $\mathbf{P}$ & $\mathbf{T}$ & $\mathbf{P}$ & $\mathbf{T}$ & $\mathbf{P}$ & $\mathbf{F}$ & \\
\hline $.1 \cdot .1^{*}$ & $N T+\Delta$ & . Pre & - IATE & $* \mid \cdot)^{\star}$ & Verr & ENDOSTATIN \\
\hline
\end{tabular}




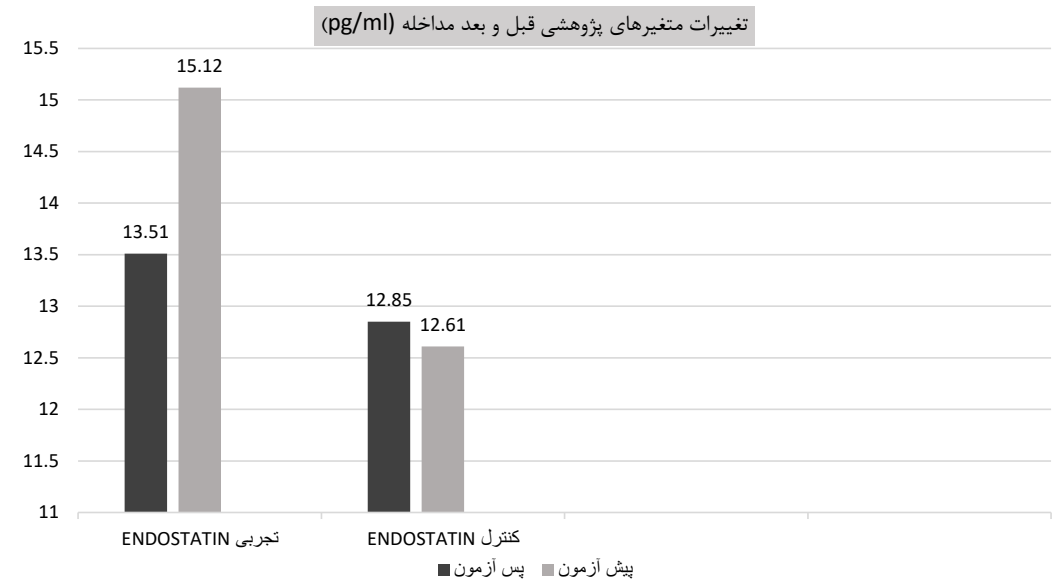

تصوير ا. ميانكين متغيرهاي دو كروه قبل و بعد از دوره تمرينى (pg/ml)

طريق سبب مهار آنزيوزثز مىشوند: ا. مهار مسير VEGF شامل الف) مهاركنندهاي ثيروزين كيناز مانند SU5416, SU6668,

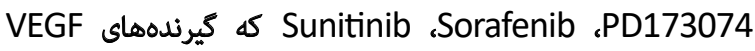

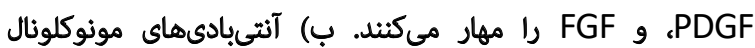

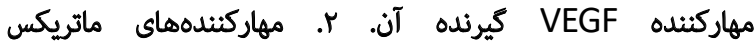

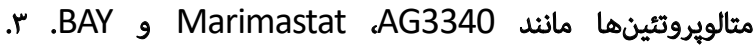

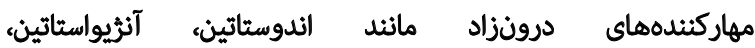

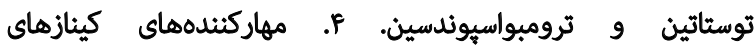

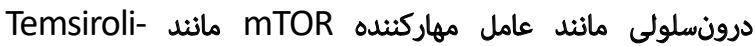

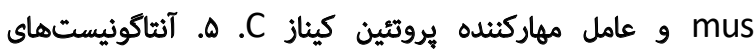

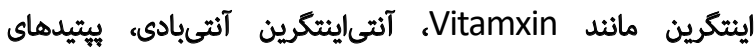
مسدودكننده عملكرد avb3 abb1 اينتكرين يا Cilengiitde. \&. سيتوكينها و كموكاينها مانند فاكتور نكروز تومور، الينترفرون أنين

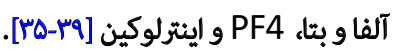

يك كام مهم در تحقيق در مورد آثريوزنز كشف مهاركنيدهايى

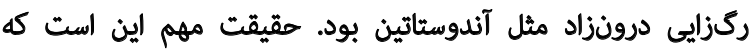

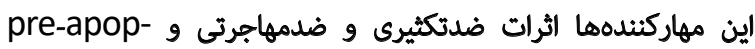
totic

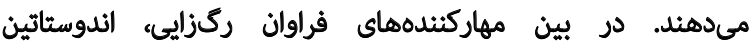

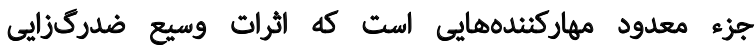

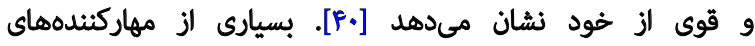

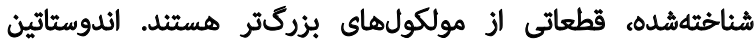

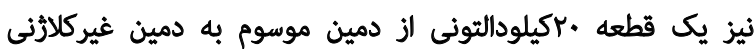

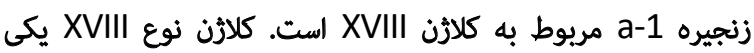

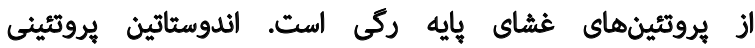

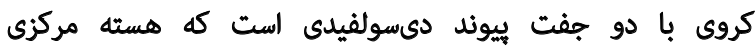

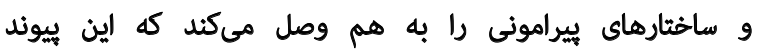
دىسولفيدى ممكن الست مسئول اعمال ضد ركزايى اندوستاتين باشد كه با اتصال به DEGF و مFGF سبب مهار ركزايى مىشود.

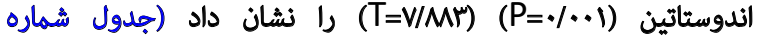

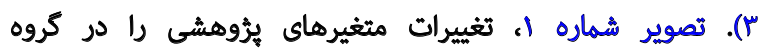

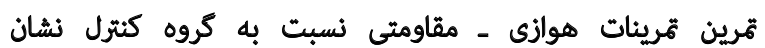

ميدهل ب̣

نتايج اين يروهش نشان داد هشت هفته ثمرين مقاومتى -

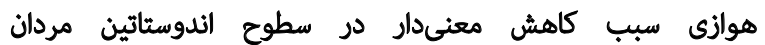

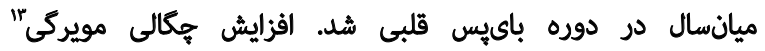

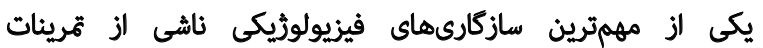

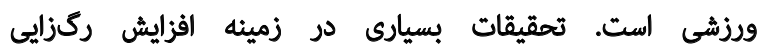

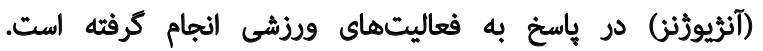
تعادل بين فرايندهاى ركزايى و ضدركزايى سبب بهبود بسياري

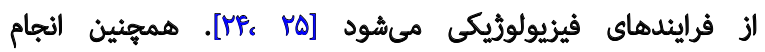

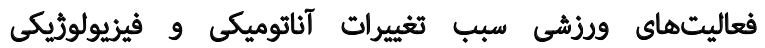

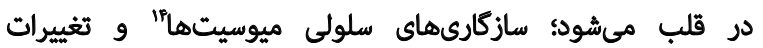

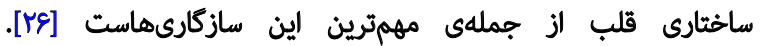

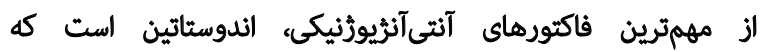

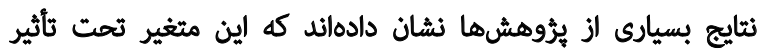

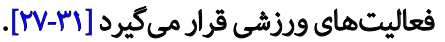

فيروهشها نشان ميدهند ثمرينات استقامتى سبب افزايش

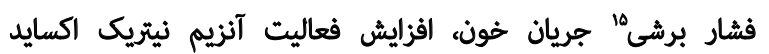

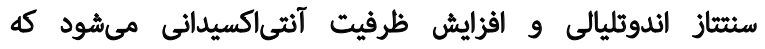

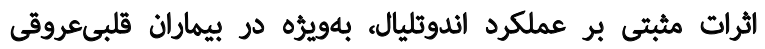

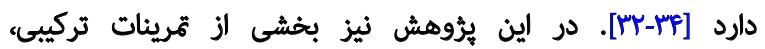

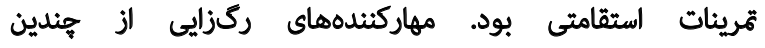

13. Increased capillary density

14. Myocytes

15. Shear stress 


\section{نتيجلكيرى}

با توجه به نتايج اين يُورهش كه به برونى اثر هشت هفته

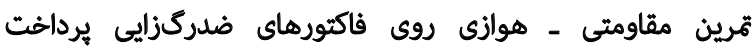

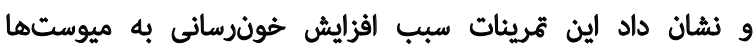

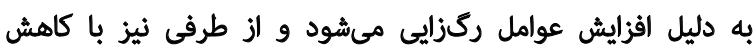

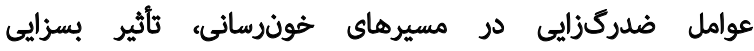

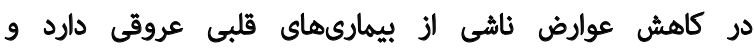

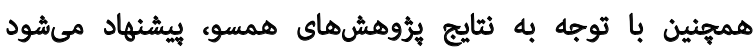

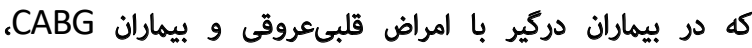

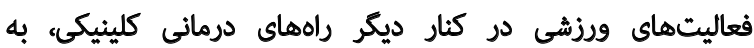

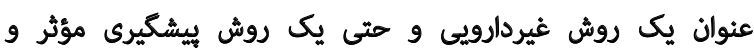
كارآمد مورد توجه قرالي كيرد.

در اين يُروهش، مردان مبتلا به فشار خون، ديابت، با وزن

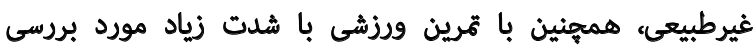

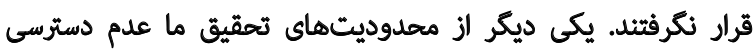

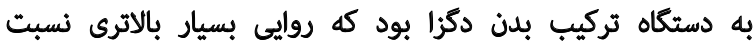

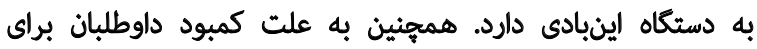
شركت در بُروهش، قادر به افزايش تعداد كروهها نبوديم.

با توجه به محدوديث بروهش حاضر در مورد يريكيرى روند

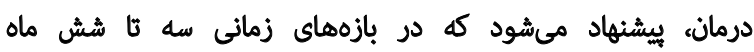

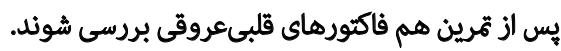

بيشنهاد مىشود اثثر برخى مكملها و ويتامينهاي مؤثر

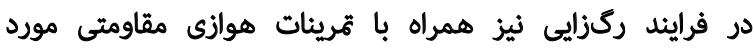
استفاده قرار كيرد.

بيشنهاد مىشود همزمان ديكر فاكتورهاى دخيل در فرايند ركزايى و بيوماكرهاي خونى مشابه نيز اندازهكيرى شوند.

ييشنهاد مىشود براى تعيين اثر جنسيت در باسخ به تمرين، كار مشابهى روى جامعه زنان انجام شود.

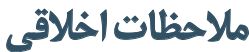

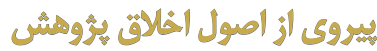

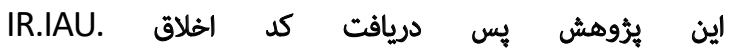
NEYSHABUR.REC.1398.018 IRCT20191228045916N1

to

اين يزوهش از رساله دكترى سيد هادى سيدى، نويسنده اول، در كروه تربيتبدنى، دانشكاه آزاد اسلامى واحد نيشابور استخراج أسيت.
همجنين الدوستاتين مانع از تخريب غشاى هايه مويرى مىشود

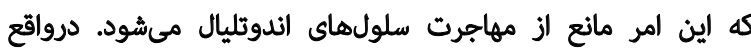

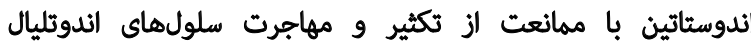

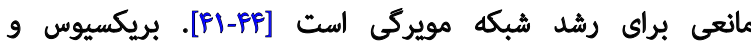

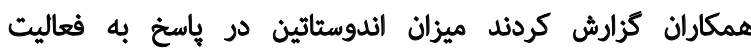

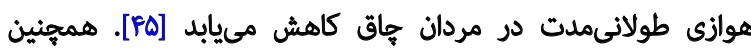

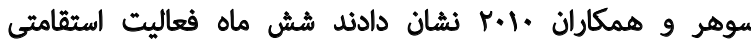

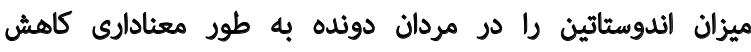

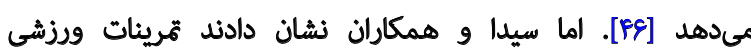
ميزان اندوسثاتين رادر مردان غيرفعال تغيير نمىدهد [ـ"ب].

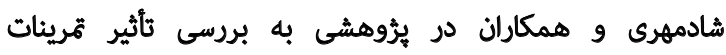

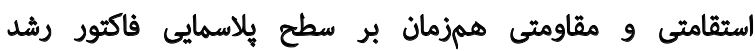

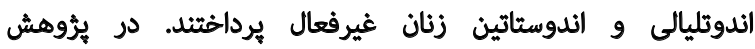

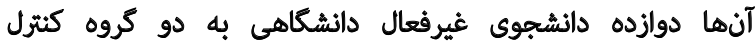

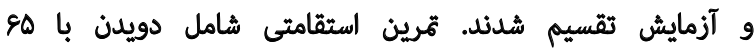

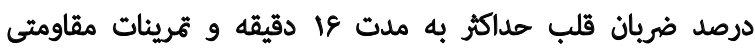

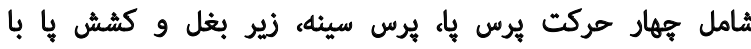

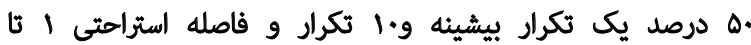

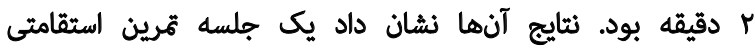

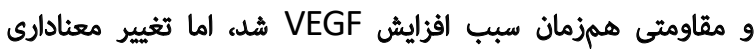

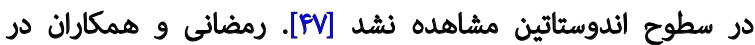

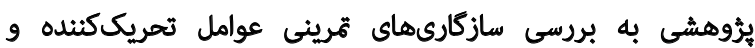

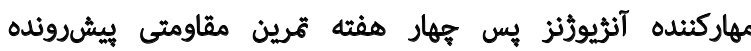

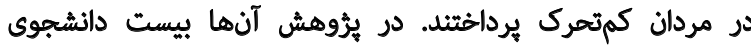

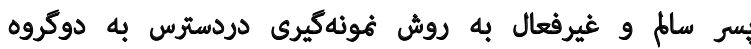

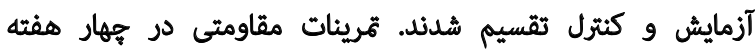

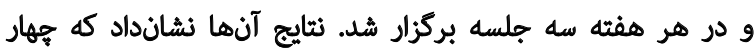

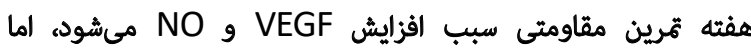

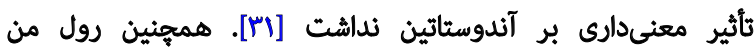

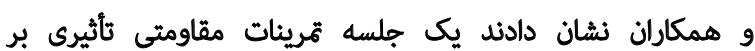

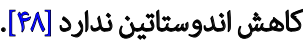

عدم اختلاف نتايج آنها با نتايج حاضر ممكن است به علت

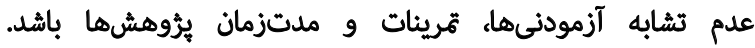

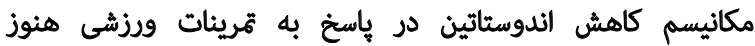

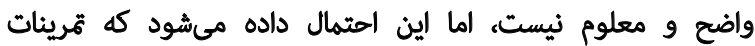

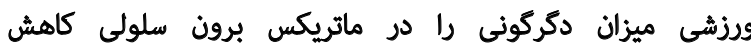

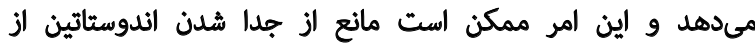

كلاثن شود [نq]

نتايج تهقيق حاضر نيز سبب كاهش سطوح بلاسمايى

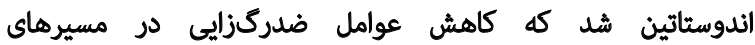

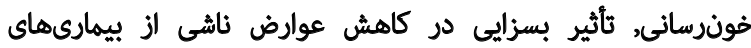

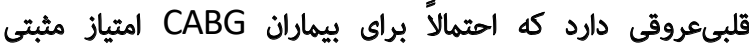

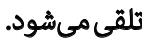




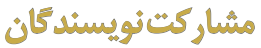

مفهومسازى و تحليل دادهها: سيد هادى سيدى: روش بُؤوهش

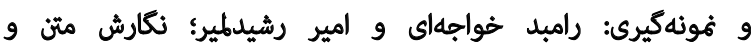
بازبينى:كليه نويسندكان.

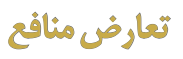

بنابر الظهار نويسندكان هيجكونه تعارض منافعى در اين يُؤهش

$$
\text { وجود ندارد. }
$$

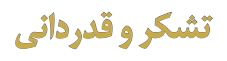

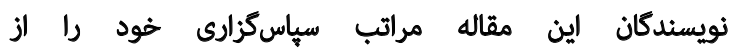

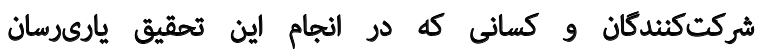

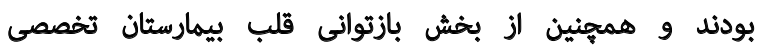

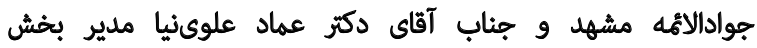

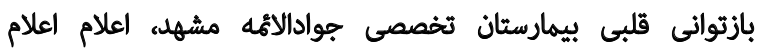
مى دارند. 


\section{References}

[1] Vahedi Kojnagh H, Rezaee Melajegh R. [Comparison of quality of life in cardiovascular patients, musculoskeletal patients and healthy subjects (Persian)]. The first national conference on lifestyle and health, 2018 February 15, Yazd. https://civilica.com/doc/747225/

[2] Vahanian A, Ferrari R. Universal definition of myocardial infarction. In: European Society of Cardiology, editor. ESC guidelines desk reference 2010: Compendium of abridged esc guidelines 2010. London: Springer Healthcare Ltd; 2010. [DOI:10.1007/978-1-907673-10-8]

[3] Rashidlamir A. [Investigation of the effect of aerobic and resistance exercises on peripheral blood mononuclear cells ABCG1 gene expression in female athletes (Persian)]. J Shahid Sadoughi Univ Med Sci. 2012; 20(1):1-9. http://jssu.ssu.ac.ir/article-1-1903-en.pdf

[4] Nazari N, Hashemi-Javaheri AA, Rashid-Lamir A, Alaviniya E. Effect of cardiac rehabilitation on strength and balance in patients after coronary artery bypass graft. Zahedan J Res Med Sci. 2014; 16(1):74-8. https:// sites.kowsarpub.com/zjrms/articles/1754.html

[5] Saadatnia A, Ebrahim K, Rashidlamir A. Echocardiographic evaluation of the effects of high-intensity interval training on cardiac morphology and function. Arch Cardiovasc Imaging. 2016; 4(1). [DOI:10.5812/ acvi.36007]

[6] Rashidlamir A, Saadatnia A. [Effects of 2 months aerobic exercis on glucose homeostasis index and cardiovascular risk factors (Persian)]. JSSU. 2011; 19(2):219-29. http://jssu.ssu.ac.ir/article-1-1503-en.html

[7] Alsabah Alavizadeh N, Rashidlamir A, Hejazi SM. Effects of eight weeks of cardiac rehabilitation training on serum levels of sirtuin1 and functional capacity of post-coronary artery bypass grafting patients. Med. Lab J. 2019; 13(2):41-7. [DOI:10.29252/mlj.13.2.41]

[8] Weiner RB, Baggish AL. Exercise-induced cardiac remodeling. Prog Cardiovasc Dis. 2012; 54(5):380-6. [DOI:10.1016/j.pcad.2012.01.006] [PMID]

[9] Olfert IM, Howlett RA, Wagner PD, Breen EC. Myocyte vascular endothelial growth factor is required for exercise-induced skeletal muscle angiogenesis. Am J Physiol Regul Integr Comp Physiol. 2010; 299(4):R1059-67. [DOI:10.1152/ajpregu.00347.2010] [PMID] [PMCID]

[10] Semenza GL. Oxygen sensing, homeostasis, and disease. N Engl J Med. 2011; 365(6):537-47. [DOI:10.1056/NEJMra1011165] [PMID]

[11] Sica A, Melillo G, Varesio L. Hypoxia: A double-edged sword of immunity. J Mol Med. 2011; 89(7):657-65. [DOI:10.1007/s00109-0110724-8] [PMID]

[12] Otrock ZK, Mahfouz RA, Makarem JA, Shamseddine Al. Understanding the biology of angiogenesis: Review of the most important molecular mechanisms. Blood Cells Mol Dis. 2007; 39(2):212-20. [DOI:10.1016/j. bcmd.2007.04.001] [PMID]

[13] Zhu H, Zhang S. Hypoxia inducible factor-1 $\alpha$ /vascular endothelial growth factor signaling activation correlates with response to radiotherapy and its inhibition reduces hypoxia-induced angiogenesis in lung cancer. J Cell Biochem. 2018; 119(9):7707-18. [DOI:10.1002/jcb.27120] [PMID]

[14] Ruge T, Carlsson AC, Larsson A, Ärnlöv J. Endostatin: A promising biomarker in the cardiovascular continuum? Biomark Med. 2017; 11(10):905-16. [DOI:10.2217/bmm-2017-0025] [PMID]

[15] Sponder M, Fritzer-Szekeres M, Marculescu R, Litschauer B, StrametzJuranek J. Physical inactivity increases endostatin and osteopontin in patients with coronary artery disease. Heart Vessels. 2016; 31(10):1603-8. [DOI:10.1007/s00380-015-0778-6] [PMID]
[16] Moholdt TT, Amundsen BH, Rustad LA, Wahba A, Løvø KT, Gullikstad $\mathrm{LR}$, et al. Aerobic interval training versus continuous moderate exercise after coronary artery bypass surgery: A randomized study of cardiovascular effects and quality of life. Am Heart J. 2009; 158(6):1031-7. [DOI:10.1016/j.ahj.2009.10.003] [PMID]

[17] Karamanlidis G, Bautista-Hernandez V, Fynn-Thompson F, del Nido $P$, Tian R. Impaired mitochondrial biogenesis precedes heart failure in right ventricular hypertrophy in congenital heart disease. Circ Heart Fail. 2011; 4(6):707-13. [DOI:10.1161/CIRCHEARTFAILURE.111.961474] [PMID] [PMCID]

[18] Freedman SB, Isner JM. Therapeutic angiogenesis for coronary artery disease. Ann Intern Med. 2002; 136(1):54-71. [DOI:10.7326/0003 4819-136-1-200201010-00011] [PMID]

[19] Hammond HK, McKirnan MD. Angiogenic gene therapy for heart disease: A review of animal studies and clinical trials. Cardiovasc Res. 2001; 49(3):561-7. [DOI:10.1016/S0008-6363(00)00257-1]

[20] Gaieni A. [Comparison of eight weeks of combined and aerobic training on functional capacity, body composition and strength in post-coronary artery bypass graft cardiac patients (Persian)]. Cardiovasc Nurs J. 2013; 2(1):34-41. http://journal.icns.org.ir/article-1-148-en.htm

[21] Ghroubi S, Elleuch W, Abid L, Abdenadher M, Kammoun S, Elleuch $\mathrm{MH}$. Effects of a low-intensity dynamic-resistance training protocol using an isokinetic dynamometer on muscular strength and aerobic capacity after coronary artery bypass grafting. Ann Phys Rehabil Med. 2013 56(2):85-101. [DOI:10.1016/j.rehab.2012.10.006] [PMID]

[22] Czarkowska-Paczek B, Bartlomiejczyk I, Przybylski J. The serum levels of growth factors: PDGF, TGF-BETA. J Physiol Pharmacol. 2006; 57(2):189-97. http://www.jpp.krakow.pl/journal/archive/06_06/articles/03 article.html

[23] Pollock ML, Franklin BA, Balady GJ, Chaitman BL, Fleg JL, Fletcher B, et al. Resistance exercise in individuals with and without cardiovascular disease: Benefits, rationale, safety, and prescription: An advisory from the committee on exercise, rehabilitation, and prevention, council on clinical cardiology, American Heart Association. Circulation. 2000; 101(7):828-33. [DOI:10.1161/01.CIR.101.7.828] [PMID]

[24] Bloor CM. Angiogenesis during exercise and training. Angiogenesis. 2005; 8(3):263-71. [DOI:10.1007/s10456-005-9013-x] [PMID]

[25] Ghahramani M, Karbalaeifar S. The effect of interval training on cardiac angiogenesis capacity in rats with myocardial infarction. Rep Health Care. 2019; 5(1):9-16. http://jrhc.miau.ac.ir/article_3114.html

[26] Smith DL, Fernhall B. Advanced cardiovascular exercise physiology. Champaign: Human Kinetics; 2011. https://books.google. com/books/about/Advanced_Cardiovascular_Exercise_Physiol. html?id=gBExM6v-XPcC

[27] Ma L, Del Soldato P, Wallace JL. Divergent effects of new cyclooxygenase inhibitors on gastric ulcer healing: shifting the angiogenic balance. Proc Natl Acad Sci U S A. 2002; 99(20):13243-7. [DOI:10.1073/ pnas.202392199] [PMID] [PMCID]

[28] Luo J, Hu X, Zhang L, Li L, Zheng H, Li M, et al. Physical exercise regulates neural stem cells proliferation and migration via SDF-1 $\alpha / C X C R 4$ pathway in rats after ischemic stroke. Neurosci Lett. 2014; 578:203-8. [DOI:10.1016/j.neulet.2014.06.059] [PMID]

[29] Rajabi H, Nasirinezhad F, Bapiran M, Ramezani F. [The effect of two weeks of severe periodic training on SDF-1 $\alpha$ protein, its receptor (CXCR4) and C-Kit in the heart of male rats (Persian)]. Armaghane Danesh. 2018 23(3):317-33. http://armaghanj.yums.ac.ir/article-1-2167-fa.html 
[30] Seida A, Wada J, Kunitomi M, Tsuchiyama Y, Miyatake N, Fujii M, et al. Serum bFGF levels are reduced in Japanese overweight men and restored by a 6-month exercise education. Int J Obes Relat Metab Disord. 2003; 27(11):1325-31. [DOI:10.1038/sj.ijo.0802408] [PMID]

[31] Karami S, Ramezani AR. [Adaptation in response of excitation and inhibition factors of angiogenesis after 4 weeks of progressive resistant training in sedentary men (Persian)]. Horizon Med Sci. 2016; 22(4):26774. [DOI:10.18869/acadpub.hms.22.4.267]

[32] Laufs U, Werner N, Link A, Endres M, Wassmann S, Jürgens $K$, et al. Physical training increases endothelial progenitor cells, inhibits neointima formation, and enhances angiogenesis. Circulation. 2004; 109(2):220-6. [DOI:10.1161/01.CIR.0000109141.48980.37] [PMID]

[33] Laufs U, Werner N, Link A, Endres M, Jürgens K, Miche E, et al. P3461 Physical training increases endothelial progenitor cells, inhibits neointima formation and enhances angiogenesis. Eur Heart J. 2003; 5(24):670. [DOI:10.1016/S0195-668X(03)96087-8]

[34] Van Craenenbroeck EM, Beckers PJ, Possemiers NM, Wuyts K, Frederix G, Hoymans VY, et al. Exercise acutely reverses dysfunction of circulating angiogenic cells in chronic heart failure. Eur Heart J. 2010; 31(15):192434. [DOI:10.1093/eurheartj/ehq058] [PMID]

[35] Wong MLH, Prawira A, Kaye AH, Hovens CM. Tumour angiogenesis: Its mechanism and therapeutic implications in malignant gliomas. J Clin Neurosci. 2009; 16(9):1119-30. [DOI:10.1016/j.jocn.2009.02.009] [PMID]

[36] Rüegg C, Hasmim M, Lejeune FJ, Alghisi GC. Antiangiogenic peptides and proteins: From experimental tools to clinical drugs. Biochim Biophys Acta. 2006; 1765(2):155-77. [DOI:10.1016/j.bbcan.2005.09.003] [PMID]

[37] Liekens S, De Clercq E, Neyts J. Angiogenesis: Regulators and clinical applications. Biochem Pharmacol. 2001; 61(3):253-70. [DOI:10.1016/ s0006-2952(00)00529-33] [PMID]

[38] Fayette J, Soria J-C, Armand J-P. Use of angiogenesis inhibitors in tumour treatment. Eur J Cancer. 2005; 41(8):1109-16. [DOI:10.1016/j. ejca.2005.02.017] [PMID]

[39] Dong X, Han ZC, Yang R. Angiogenesis and antiangiogenic therapy in hematologic malignancies. Crit Rev Oncol Hematol. 2007; 62(2):105-18. [DOI:10.1016/j.critrevonc.2006.11.006] [PMID]

[40] Abdollahi A, Hlatky L, Huber PE. Endostatin: The logic of antiangiogenic therapy. Drug Resist Updat. 2005; 8(1-2):59-74. [DOI:10.1016/j. drup.2005.03.001] [PMID]

[41] O'Reilly MS, Boehm T, Shing Y, Fukai N, Vasios G, Lane WS, et al. Endostatin: An endogenous inhibitor of angiogenesis and tumor growth. Cell. 1997; 88(2):277-85. [DOI:10.1016/S0092-8674(00)81848-6]

[42] Wen W, Moses MA, Wiederschain D, Arbiser JL, Folkman J. The generation of endostatin is mediated by elastase. Cancer Res. 1999; 59(24):6052-6. https://cancerres.aacrjournals.org/content/59/24/6052

[43] Felbor U, Dreier L, Bryant RA, Ploegh HL, Olsen BR, Mothes W. Secreted cathepsin L generates endostatin from collagen XVIII. EMBO J. 2000; 19(6):1187-94. [DOI:10.1093/emboj/19.6.1187] [PMID] [PMCID]

[44] Tan H, Yang S, Feng Y, Liu C, Cao J, Mu G, et al. Characterization and secondary structure analysis of endostatin covalently modified by polyethylene glycol and low molecular weight heparin. J Biochem. 2008; 144(2):207-13. [DOI:10.1093/jb/mvn060] [PMID]

[45] Brixius K, Schoenberger S, Ladage D, Knigge H, Falkowski G, Hellmich $M$, et al. Long-term endurance exercise decreases antiangiogenic endostatin signalling in overweight men aged $50-60$ years. Br J Sports Med. 2008; 42(2):126-9. [DOI:10.1136/bjsm.2007.035188] [PMID]
[46] Suhr F, Rosenwick C, Vassiliadis A, Bloch W, Brixius K. Regulation of extracellular matrix compounds involved in angiogenic processes in shortand long-track elite runners. Scand J Med Sci Sports. 2010; 20(3):441-8. [DOI:10.1111/j.1600-0838.2009.00960.x] [PMID]

[47] Shadmehri S, Ahmadi M. The Effect of Concurrent Endurance and Resistance Exercise on Plasma Levels of Vascular Endothelial Growth Factor and Endostatin in Inactive Women. Report of Health Care. 2016 2(1):38-45. http://jrhc.miau.ac.ir/article_2794.html

[48] Rullman E, Rundqvist $H$, Wågsäter D, Fischer $H$, Eriksson P, Sundberg $\mathrm{CJ}$, et al. A single bout of exercise activates matrix metalloproteinase in human skeletal muscle. J Appl Physiol. 2007; 102(6):2346-51. [DOI:10.1152/japplphysiol.00822.2006] [PMID]

[49] Gu J-W, Gadonski G, Wang J, Makey I, Adair TH. Exercise increases endostatin in circulation of healthy volunteers. BMC Physiol. 2004; 4:2. [DOI:10.1186/1472-6793-4-2] [PMID] [PMCID] 